\title{
On generalized equilibrium problems and strictly pseudocontractive mappings in Hilbert spaces
}

\author{
Chunyan Huang ${ }^{1}$ and Xiaoyan $\mathrm{Ma}^{2 *}$
}

\footnotetext{
"Correspondence: kfmaxy@yeah.net

${ }^{2}$ Basic Experimental \& Teaching

Center, Henan University, Kaifeng 475000, China

Full list of author information is available at the end of the article
}

\begin{abstract}
In this article, a mean iterative algorithm is investigated for finding a common element in the solution set of generalized equilibrium problems and in the fixed point set of strictly pseudocontractive mappings. Strong convergence of the mean iterative algorithm is obtained in the framework of Hilbert spaces.
\end{abstract}

Keywords: variational inequality; strictly pseudocontractive mapping; nonexpansive mapping; inverse-strongly monotone mapping; equilibrium problem

\section{Introduction-preliminaries}

Many important problems have reformulations which require finding solutions of classical variational inequalities, for instance, image recovery, inverse problems, transportation problems, fixed point problems and optimization problems; see [1-11] and the references therein. Equilibrium problems, which include the classical variational inequalities as special cases, have been recently extensively investigated; see [12-26] and the references therein. In this paper, we study an equilibrium problem via fixed point methods. Global convergence of the fixed point algorithm is obtained. Throughout this paper, we always assume that $H$ is a real Hilbert space with the inner product $\langle\cdot, \cdot\rangle$ and the norm $\|\cdot\|$. Let $C$ be a nonempty closed convex subset of $H$, and let $P_{C}$ be a metric projection from $H$ onto $C$.

Let $S: C \rightarrow C$ be a mapping. In this paper, we use $F(S)$ to denote the fixed point set of $S$. Recall that the mapping $S$ is said to be nonexpansive if

$$
\|S x-S y\| \leq\|x-y\| \quad \forall x, y \in C .
$$

$S$ is said to be $k$-strictly pseudocontractive if there exists a constant $k \in[0,1)$ such that

$$
\|S x-S y\|^{2} \leq\|x-y\|^{2}+k\|(x-S x)-(y-S y)\|^{2} \quad \forall x, y \in C .
$$

The class of strictly pseudocontractive mappings was introduced by Browder and Petryshyn [27] in 1967. It is easy to see that the class of strictly pseudocontractive mappings includes the class of nonexpansive mappings as a special case. If $k=1$, then it is called a pseudocontractive mapping.

(c) 2014 Huang and Ma; licensee Springer. This is an Open Access article distributed under the terms of the Creative Commons Attribution License (http://creativecommons.org/licenses/by/2.0), which permits unrestricted use, distribution, and reproduction in any medium, provided the original work is properly cited. 
Recall that a set-valued mapping $T: H \rightarrow 2^{H}$ is said to be monotone if for all $x, y \in H$, $f \in T x$ and $g \in T y$ imply $\langle x-y, f-g\rangle>0$. A monotone mapping $T: H \rightarrow 2^{H}$ is maximal if the graph $\operatorname{Graph}(T)$ of $R$ is not properly contained in the graph of any other monotone mapping. It is known that a monotone mapping $T$ is maximal if and only if, for any $(x, f) \in$ $H \times H,\langle x-y, f-g\rangle \geq 0$ for all $(y, g) \in \operatorname{Graph}(T)$ implies $f \in T x$. Let $A$ be a monotone mapping of $C$ into $H$, and let $N_{C} v$ be a normal cone to $C$ at $v \in C$, i.e.,

$$
N_{C} v=\{w \in H:\langle v-u, w\rangle \geq 0 \forall u \in C\}
$$

and define a mapping $R$ on $C$ by

$$
T v= \begin{cases}A v+N_{C} v, & v \in C, \\ \varnothing, & v \notin C .\end{cases}
$$

Then $T$ is maximal monotone and $0 \in R v$ if and only if $\langle A v, u-v\rangle \geq 0$ for all $u \in C$; see [28] and the references therein.

Let $A: C \rightarrow H$ be a mapping. Recall that $A$ is said to be monotone if

$$
\langle A x-A y, x-y\rangle \geq 0 \quad \forall x, y \in C .
$$

$A$ is said to be inverse-strongly monotone if there exists a constant $\alpha>0$ such that

$$
\langle A x-A y, x-y\rangle \geq \alpha\|A x-A y\|^{2} \quad \forall x, y \in C .
$$

For such a case, $A$ is also called an $\alpha$-inverse-strongly monotone mapping. It is easy to see that if $A$ is an inverse-strongly monotone mapping, then the mapping $I-A$ is a strictly pseudocontractive mapping.

Let $T: C \rightarrow H$ be an inverse-strongly monotone mapping, and let $F$ be a bifunction of $C \times C$ into $\mathbb{R}$, where $\mathbb{R}$ denotes the set of real numbers. In this paper, we consider the following generalized equilibrium problem:

$$
\text { Find } x \in C \text { such that } F(x, y)+\langle T x, y-x\rangle \geq 0 \quad \forall y \in C \text {. }
$$

In this paper, we use $\operatorname{EP}(F, T)$ to denote the solution set of problem (1.1).

Next, we give two special cases of problem (1.1).

(a) If $T \equiv 0$, then the generalized equilibrium problem (1.1) is reduced to the following equilibrium problem:

$$
\text { Find } x \in C \text { such that } F(x, y) \geq 0 \quad \forall y \in C \text {. }
$$

In this paper, we use $\operatorname{EP}(F)$ to denote the solution set of problem (1.2). We remark here that problem (1.2) was first introduced by Fan [29].

(b) If $F \equiv 0$, then problem (1.1) is reduced to the classical variational inequality: Find $x \in C$ such that

$$
\langle T x, y-x\rangle \geq 0 \quad \forall y \in C .
$$


In this paper, we use $\operatorname{VI}(C, T)$ to denote the solution set of variational inequality

(1.3). It is well know that $x \in C$ is a solution to (1.3) if and only if $x$ is a fixed point of the mapping $P_{C}(I-r T)$, where $r>0$ is a constant and $I$ is the identity mapping.

To study the generalized equilibrium problem (1.1), we may assume that $F$ satisfies the following conditions:

(A1) $F(x, x)=0$ for all $x \in C$;

(A2) $F$ is monotone, i.e., $F(x, y)+F(y, x) \leq 0$ for all $x, y \in C$;

(A3) for each $x, y, z \in C$,

$$
\limsup _{t \downarrow 0} F(t z+(1-t) x, y) \leq F(x, y)
$$

(A4) for each $x \in C, y \mapsto F(x, y)$ is convex and weakly lower semicontinuous.

Recently, many authors investigated problems (1.1), (1.2) and (1.3) based on iterative methods. In 2003, Takahashi and Toyoda [30] investigated fixed points of nonexpansive mappings and solutions of variational inequality (1.3). They obtained the following results. Let $A$ be an $\alpha$-inverse-strongly monotone mapping of $C$ into $H$, and let $S$ be a nonexpansive mapping of $C$ into itself such that $F(S) \cap \operatorname{VI}(C, A) \neq \emptyset$. Let $\left\{x_{n}\right\}$ be a sequence generated by

$$
x_{0} \in C, \quad x_{n+1}=\alpha_{n} x_{n}+\left(1-\alpha_{n}\right) S P_{C}\left(x_{n}-\lambda_{n} A x_{n}\right) \quad \forall n \geq 0,
$$

where $\lambda_{n} \in[a, b]$ for some $a, b \in(0,2 \alpha)$ and $\alpha_{n} \in[c, d]$ for some $c, d \in(0,1)$. Then $\left\{x_{n}\right\}$ converges weakly to $z \in F(S) \cap \operatorname{VI}(C, A)$, where $z=\lim _{n \rightarrow \infty} P_{F(S) \cap \mathrm{VI}(C, A)} x_{n}$.

Recently, Tada and Takahashi [14] investigated fixed points of nonexpansive mappings and solutions of equilibrium problem (1.2). They obtained the following result. Let $F$ be a bifunction from $C \times C$ to $\mathbb{R}$ satisfying (A1)-(A4), and let $S$ be a nonexpansive mapping of $C$ into $H$ such that $F(S) \cap \operatorname{EP}(F) \neq \emptyset$. Let $\left\{x_{n}\right\}$ and $\left\{u_{n}\right\}$ be sequences generated by $x_{1}=x \in H$, and let

$$
\left\{\begin{array}{l}
u_{n} \in C \text { such that } F\left(u_{n}, u\right)+\frac{1}{r_{n}}\left\langle u-u_{n}, u_{n}-x_{n}\right\rangle \geq 0 \quad \forall u \in C, \\
x_{n+1}=\alpha_{n} x_{n}+\left(1-\alpha_{n}\right) S u_{n},
\end{array}\right.
$$

where $\left\{\alpha_{n}\right\} \subset[a, b]$ for some $a, b \in(0,1)$ and $\left\{r_{n}\right\} \subset(0, \infty)$ satisfies $\liminf _{n \rightarrow \infty} r_{n}>0$. Then $\left\{x_{n}\right\}$ converges weakly to $w \in F(S) \cap \operatorname{EP}(F)$, where $w=\lim _{n \rightarrow \infty} P_{F(S) \cap \operatorname{EP}(F)} x_{n}$.

In this paper, motivated by the above results, we investigate fixed points of strictly pseudocontractive mappings and solutions of equilibrium problem (1.1). Weak convergence theorems for common solutions are established in Hilbert spaces. Applications of the main results are also provided. In order to prove our main results, we also need the following lemmas.

Lemma 1.1 [27, 31] Let $C$ be a nonempty closed convex subset of a real Hilbert space $H$, and let $S: C \rightarrow C$ be a k-strict pseudocontraction with a fixed point. Define $S: C \rightarrow C$ by $S_{a} x=a x+(1-a) S x$ for each $x \in C$. If $a \in[k, 1)$, then $S_{a}$ is nonexpansive with $F\left(S_{a}\right)=F(S)$.

Lemma 1.2 [1] Let $C$ be a nonempty closed convex subset of $H$, and let $F: C \times C \rightarrow \mathbb{R}$ be a bifunction satisfying (A1)-(A4). Then, for any $r>0$ and $x \in H$, there exists $z \in C$ such that

$$
F(z, y)+\frac{1}{r}\langle y-z, z-x\rangle \geq 0 \quad \forall y \in C .
$$


Further, define

$$
T_{r} x=\left\{z \in C: F(z, y)+\frac{1}{r}\langle y-z, z-x\rangle \geq 0 \forall y \in C\right\}
$$

for all $r>0$ and $x \in H$. Then the following hold:

(a) $T_{r}$ is single-valued;

(b) $T_{r}$ is firmly nonexpansive, i.e., for any $x, y \in H$,

$$
\left\|T_{r} x-T_{r} y\right\|^{2} \leq\left\langle T_{r} x-T_{r} y, x-y\right\rangle
$$

(c) $F\left(T_{r}\right)=\mathrm{EP}(F)$;

(d) $\mathrm{EP}(F)$ is closed and convex.

Lemma 1.3 [32] Let $H$ be a Hilbert space and $0<p \leq t_{n} \leq q<1$ for all $n \geq 1$. Suppose that $\left\{x_{n}\right\}$ and $\left\{y_{n}\right\}$ are sequences in $H$ such that

$$
\limsup _{n \rightarrow \infty}\left\|x_{n}\right\| \leq r, \quad \limsup _{n \rightarrow \infty}\left\|y_{n}\right\| \leq r
$$

and

$$
\lim _{n \rightarrow \infty}\left\|t_{n} x_{n}+\left(1-t_{n}\right) y_{n}\right\|=r
$$

hold for some $r \geq 0$. Then $\lim _{n \rightarrow \infty}\left\|x_{n}-y_{n}\right\|=0$.

Lemma 1.4 [33] Let $C$ be a nonempty closed convex subset of a Hilbert space $H$, and let $S: C \rightarrow C$ be a k-strict pseudocontraction. Then

(a) $S$ is $\frac{1+k}{1-k}$-Lipschitz;

(b) $I-S$ is demi-closed, i.e., if $\left\{x_{n}\right\}$ is a sequence in $C$ with $x_{n} \rightarrow x$ and $x_{n}-S x_{n} \rightarrow 0$, then $x \in F(S)$.

\section{Main results}

Now, we are in a position to show the main results of the article.

Theorem 2.1 Let $C$ be a nonempty closed convex subset of a real Hilbert space H. Let $T: C \rightarrow H$ be a $\lambda$-inverse-strongly monotone mapping, and let $F$ be a bifunction from $C \times C$ to $\mathbb{R}$ which satisfies (A1)-(A4). Let $S: C \rightarrow C$ be a $k$-strict pseudocontraction. Assume that $\mathcal{F}:=\operatorname{EP}(F, T) \cap F(S)$ is not empty. Let $\left\{\alpha_{n}\right\},\left\{\beta_{n}\right\},\left\{\gamma_{n}\right\}$ and $\left\{\delta_{n}\right\}$ be sequences in $(0,1)$. Let $\left\{r_{n}\right\}$ be a sequence in $(0,2 \lambda)$, and let $\left\{e_{n}\right\}$ be a bounded sequence in $C$. Let $\left\{x_{n}\right\}$ be a sequence generated in the following manner:

$$
\left\{\begin{array}{l}
x_{1} \in C, \\
F\left(u_{n}, u\right)+\left\langle T x_{n}, u-u_{n}\right\rangle+\frac{1}{r_{n}}\left\langle u-u_{n}, u_{n}-x_{n}\right\rangle \geq 0 \quad \forall u \in C, \\
x_{n+1}=\alpha_{n} x_{n}+\beta_{n}\left(\delta_{n} u_{n}+\left(1-\delta_{n}\right) S u_{n}\right)+\gamma_{n} e_{n} \quad \forall n \geq 1 .
\end{array}\right.
$$

Assume that the sequences $\left\{\alpha_{n}\right\},\left\{\beta_{n}\right\},\left\{\gamma_{n}\right\},\left\{\delta_{n}\right\}$ and $\left\{r_{n}\right\}$ satisfy the following restrictions: $0<a \leq \alpha_{n} \leq a^{\prime}<1,0 \leq k \leq \delta_{n} \leq b<1,0<c \leq r_{n} \leq d<2 \lambda$ and $\sum_{n=1}^{\infty} \gamma_{n}<\infty$. Then the sequence $\left\{x_{n}\right\}$ converges weakly to some point $\bar{x} \in \mathcal{F}$, where $\bar{x}=\lim _{n \rightarrow \infty} P_{\mathcal{F}} x_{n}$. 
Proof First, we show that the sequences $\left\{x_{n}\right\}$ and $\left\{u_{n}\right\}$ are bounded. Putting $S_{n}=\delta_{n} I+(1-$ $\left.\delta_{n}\right) S$, we see from Lemma 1.1 that $S_{n}$ is nonexpansive and $F\left(S_{n}\right)=F(S)$. Note that

$$
\begin{aligned}
\left\|\left(I-r_{n} T\right) x-\left(I-r_{n} T\right) y\right\|^{2} & =\left\|(x-y)-r_{n}(T x-T y)\right\|^{2} \\
& =\|x-y\|^{2}-2 r_{n}\langle x-y, T x-T y\rangle+r_{n}^{2}\|T x-T y\|^{2} \\
& \leq\|x-y\|^{2}-r_{n}\left(2 \lambda-r_{n}\right)\|T x-T y\|^{2} \\
& \leq\|x-y\|^{2} \quad \forall x, y \in C .
\end{aligned}
$$

This proves that the mapping $I-r_{n} T$ is also nonexpansive. Fixing $p \in \mathcal{F}$, we find from Lemma 1.2 that $p=S p=T_{r_{n}}\left(I-r_{n} T\right) p$. Since

$$
\left\|u_{n}-p\right\| \leq\left\|T_{r_{n}}\left(I-r_{n} T\right) x_{n}-T_{r_{n}}\left(I-r_{n} T\right) p\right\| \leq\left\|x_{n}-p\right\|,
$$

we find that

$$
\begin{aligned}
\left\|x_{n+1}-p\right\| & \leq \alpha_{n}\left\|x_{n}-p\right\|+\beta_{n}\left\|S_{n} u_{n}-p\right\|+\gamma_{n}\left\|e_{n}-p\right\| \\
& \leq \alpha_{n}\left\|x_{n}-p\right\|+\beta_{n}\left\|u_{n}-p\right\|+\gamma_{n}\left\|e_{n}-p\right\| \\
& \leq\left(1-\gamma_{n}\right)\left\|x_{n}-p\right\|+\gamma_{n}\left\|e_{n}-p\right\| .
\end{aligned}
$$

This implies that $\lim _{n \rightarrow \infty}\left\|x_{n}-p\right\|$ exists. This shows that $\left\{x_{n}\right\}$ is bounded, so is $\left\{u_{n}\right\}$. Since $\|\cdot\|^{2}$ is convex, we find that

$$
\begin{aligned}
\left\|x_{n+1}-p\right\|^{2} & \leq \alpha_{n}\left\|x_{n}-p\right\|^{2}+\beta_{n}\left\|S_{n} u_{n}-p\right\|^{2}+\gamma_{n}\left\|e_{n}-p\right\|^{2} \\
& \leq \alpha_{n}\left\|x_{n}-p\right\|^{2}+\beta_{n}\left\|u_{n}-p\right\|^{2}+\gamma_{n}\left\|e_{n}-p\right\|^{2} \\
& \leq \alpha_{n}\left\|x_{n}-p\right\|^{2}+\beta_{n}\left\|\left(I-r_{n} T\right) x_{n}-p\right\|^{2}+\gamma_{n}\left\|e_{n}-p\right\|^{2} \\
& \leq\left(1-\gamma_{n}\right)\left\|x_{n}-p\right\|^{2}-r_{n}\left(2 \lambda-r_{n}\right) \beta_{n}\left\|T x_{n}-T p\right\|^{2}+\gamma_{n}\left\|e_{n}-p\right\|^{2} .
\end{aligned}
$$

It follows that

$$
r_{n}\left(2 \lambda-r_{n}\right) \beta_{n}\left\|T x_{n}-T p\right\|^{2} \leq\left(1-\gamma_{n}\right)\left\|x_{n}-p\right\|^{2}-\left\|x_{n+1}-p\right\|^{2}+\gamma_{n}\left\|e_{n}-p\right\|^{2} .
$$

This yields that

$$
\lim _{n \rightarrow \infty}\left\|T x_{n}-T p\right\|=0
$$

Using Lemma 1.2, we see that

$$
\begin{aligned}
\left\|u_{n}-p\right\|^{2} \leq & \left\langle\left(I-r_{n} T\right) x_{n}-\left(I-r_{n} T\right) p, u_{n}-p\right\rangle \\
= & \frac{1}{2}\left(\left\|\left(I-r_{n} T\right) x_{n}-\left(I-r_{n} T\right) p\right\|^{2}+\left\|u_{n}-p\right\|^{2}\right. \\
& \left.-\left\|\left(I-r_{n} T\right) x_{n}-\left(I-r_{n} T\right) p-\left(u_{n}-p\right)\right\|^{2}\right) \\
\leq & \frac{1}{2}\left(\left\|x_{n}-p\right\|^{2}+\left\|u_{n}-p\right\|^{2}-\left\|x_{n}-u_{n}-r_{n}\left(T x_{n}-T p\right)\right\|^{2}\right)
\end{aligned}
$$




$$
\begin{aligned}
= & \frac{1}{2}\left(\left\|x_{n}-p\right\|^{2}+\left\|u_{n}-p\right\|^{2}-\left(\left\|x_{n}-u_{n}\right\|^{2}\right.\right. \\
& \left.\left.-2 r_{n}\left\langle x_{n}-u_{n}, T x_{n}-T p\right\rangle+r_{n}^{2}\left\|T x_{n}-T p\right\|^{2}\right)\right) .
\end{aligned}
$$

This implies that

$$
\left\|u_{n}-p\right\|^{2} \leq\left\|x_{n}-p\right\|^{2}-\left\|x_{n}-u_{n}\right\|^{2}+2 r_{n}\left\|x_{n}-u_{n}\right\|\left\|T x_{n}-T p\right\|
$$

Since $\|\cdot\|^{2}$ is convex, we find that

$$
\begin{aligned}
\left\|x_{n+1}-p\right\|^{2} & \leq \alpha_{n}\left\|x_{n}-p\right\|^{2}+\beta_{n}\left\|S_{n} u_{n}-p\right\|^{2}+\gamma_{n}\left\|e_{n}-p\right\|^{2} \\
& \leq \alpha_{n}\left\|x_{n}-p\right\|^{2}+\beta_{n}\left\|u_{n}-p\right\|^{2}+\gamma_{n}\left\|e_{n}-p\right\|^{2} \\
& \leq\left\|x_{n}-p\right\|^{2}-\beta_{n}\left\|x_{n}-u_{n}\right\|^{2}+2 r_{n} \beta_{n}\left\|x_{n}-u_{n}\right\|\left\|T x_{n}-T p\right\|+\gamma_{n}\left\|e_{n}-p\right\|^{2} .
\end{aligned}
$$

It follows that

$$
\beta_{n}\left\|x_{n}-u_{n}\right\|^{2} \leq\left\|x_{n}-p\right\|^{2}-\left\|x_{n+1}-p\right\|^{2}+2 r_{n}\left\|x_{n}-u_{n}\right\|\left\|T x_{n}-T p\right\|+\gamma_{n}\left\|e_{n}-p\right\|^{2} \text {. }
$$

Using the restrictions imposed on the sequences, we obtain from (2.2) that

$$
\lim _{n \rightarrow \infty}\left\|x_{n}-u_{n}\right\|=0
$$

Since $\left\{x_{n}\right\}$ is bounded, we see that there exits a subsequence $\left\{x_{n_{i}}\right\}$ of $\left\{x_{n}\right\}$ which converges weakly to $\bar{x}$. Using (2.3), we also find that $\left\{u_{n_{i}}\right\}$ converges weakly to $\bar{x}$. Note that

$$
F\left(u_{n}, u\right)+\left\langle T x_{n}, u-u_{n}\right\rangle+\frac{1}{r_{n}}\left\langle u-u_{n}, u_{n}-x_{n}\right\rangle \geq 0 \quad \forall u \in C
$$

From (A2), we see that

$$
\left\langle T x_{n}, u-u_{n}\right\rangle+\frac{1}{r_{n}}\left\langle u-u_{n}, u_{n}-x_{n}\right\rangle \geq F\left(u, u_{n}\right) \quad \forall u \in C .
$$

Replacing $n$ by $n_{i}$, we arrive at

$$
\left\langle T x_{n_{i}}, u-u_{n_{i}}\right\rangle+\frac{1}{r_{n_{i}}}\left\langle u-u_{n_{i}}, u_{n_{i}}-x_{n_{i}}\right\rangle \geq F\left(u, u_{n_{i}}\right) \quad \forall u \in C .
$$

For $t$ with $0<t \leq 1$ and $u \in C$, let $u_{t}=t u+(1-t) \bar{x}$. Since $u \in C$ and $\bar{x} \in C$, we have $u_{t} \in C$. It follows from (2.4) that

$$
\begin{aligned}
\left\langle u_{t}-u_{n_{i}}, T u_{t}\right\rangle \geq & \left\langle u_{t}-u_{n_{i}}, T u_{t}\right\rangle-\left\langle T x_{n_{i}}, u_{t}-u_{n_{i}}\right\rangle \\
& -\left\langle u_{t}-u_{n_{i}}, \frac{u_{n_{i}}-x_{n_{i}}}{r_{n_{i}}}\right\rangle+F\left(u_{t}, u_{n_{i}}\right) \\
= & \left\langle u_{t}-u_{n_{i}}, T u_{t}-T u_{n_{i}}\right\rangle+\left\langle u_{t}-u_{n_{i}}, T u_{n_{i}}-T x_{n_{i}}\right\rangle \\
& -\left\langle u_{t}-u_{n_{i}}, \frac{u_{n_{i}}-x_{n_{i}}}{r_{n_{i}}}\right\rangle+F\left(u_{t}, u_{n_{i}}\right) .
\end{aligned}
$$


Using (2.3), we have $T u_{n_{i}}-T x_{n_{i}} \rightarrow 0$ as $i \rightarrow \infty$. Using the monotonicity of $T$, we see that $\left\langle u_{t}-u_{n_{i}}, T u_{t}-T u_{n_{i}}\right\rangle \geq 0$. It follows from (A4) that

$$
\left\langle u_{t}-\bar{x}, T u_{t}\right\rangle \geq F\left(u_{t}, \bar{x}\right)
$$

Using (A1) and (A4), we see from (2.6) that

$$
\begin{aligned}
0 & =F\left(u_{t}, u_{t}\right) \leq t F\left(u_{t}, u\right)+(1-t) F\left(u_{t}, \bar{x}\right) \\
& \leq t F\left(u_{t}, u\right)+(1-t)\left\langle u_{t}-\bar{x}, T u_{t}\right\rangle \\
& =t F\left(u_{t}, u\right)+(1-t) t\left\langle u-\bar{x}, T u_{t}\right\rangle .
\end{aligned}
$$

It follows that $F\left(u_{t}, u\right)+(1-t)\left\langle u-\bar{x}, T u_{t}\right\rangle \geq 0$. Letting $t \rightarrow 0$ in the above inequality, we arrive at $F(\bar{x}, u)+\langle u-\bar{x}, T \bar{x}\rangle \geq 0$. Hence, $\bar{x} \in \operatorname{EP}(F, T)$.

Next, we are in a position to show that $\bar{x} \in F(S)$. Note that $\lim _{n \rightarrow \infty}\left\|x_{n}-p\right\|$ exists. We may assume that $\lim _{n \rightarrow \infty}\left\|x_{n}-p\right\|=d>0$. Note that

$$
\lim _{n \rightarrow \infty}\left\|x_{n+1}-p\right\|=\lim _{n \rightarrow \infty}\left\|\beta_{n}\left(S_{n} u_{n}-p+\gamma_{n}\left(e_{n}-x_{n}\right)\right)+\left(1-\beta_{n}\right)\left(x_{n}-p+\gamma_{n}\left(e_{n}-x_{n}\right)\right)\right\|=d
$$

Since

$$
\begin{aligned}
\left\|S_{n} u_{n}-p+\gamma_{n}\left(e_{n}-x_{n}\right)\right\| & \leq\left\|S_{n} u_{n}-p\right\|+\gamma_{n}\left\|e_{n}-x_{n}\right\| \\
& \leq\left\|u_{n}-p\right\|+\gamma_{n}\left\|e_{n}-x_{n}\right\| \\
& \leq\left\|x_{n}-p\right\|+\gamma_{n}\left\|e_{n}-x_{n}\right\|,
\end{aligned}
$$

we find that $\lim _{n \rightarrow \infty}\left\|S_{n} x_{n}-p+\gamma_{n}\left(e_{n}-x_{n}\right)\right\| \leq d$. Since $\left\|x_{n}-p+\gamma_{n}\left(e_{n}-x_{n}\right)\right\| \leq\left\|x_{n}-p\right\|+$ $\gamma_{n}\left\|e_{n}-x_{n}\right\|$, we find that $\lim _{n \rightarrow \infty}\left\|x_{n}-p+\gamma_{n}\left(e_{n}-x_{n}\right)\right\| \leq d$. Using Lemma 1.3, we obtain that $\lim _{n \rightarrow \infty}\left\|S_{n} u_{n}-x_{n}\right\|=0$. In view of

$$
S u_{n}-x_{n}=\frac{S_{n} u_{n}-x_{n}}{1-\delta_{n}}+\frac{\delta_{n}\left(x_{n}-u_{n}\right)}{1-\delta_{n}},
$$

it follows that $\lim _{n \rightarrow \infty}\left\|S u_{n}-x_{n}\right\|=0$. Note that $\left\|S x_{n}-x_{n}\right\| \leq\left\|S x_{n}-S u_{n}\right\|+\left\|S u_{n}-x_{n}\right\|$. Using Lemma 1.4, we find that $\lim _{n \rightarrow \infty}\left\|S x_{n}-x_{n}\right\|=0$. It follows from Lemma 1.4 that $\bar{x} \in F(S)$. This proves that $\bar{x} \in \mathcal{F}$. Assume that there exits another subsequence $\left\{x_{n_{j}}\right\}$ of $\left\{x_{n}\right\}$ such that $\left\{x_{n_{j}}\right\}$ converges weakly to $x^{\prime}$. We can find that $x^{\prime} \in \mathcal{F}$. If $\bar{x} \neq x^{\prime}$, we get from the Opial condition [34] that

$$
\begin{aligned}
\lim _{n \rightarrow \infty}\left\|x_{n}-\bar{x}\right\| & =\liminf _{i \rightarrow \infty}\left\|x_{n_{i}}-\bar{x}\right\|<\liminf _{i \rightarrow \infty}\left\|x_{n_{i}}-x^{\prime}\right\| \\
& =\lim _{n \rightarrow \infty}\left\|x_{n}-x^{\prime}\right\|=\liminf _{j \rightarrow \infty}\left\|x_{n_{j}}-x^{\prime}\right\| \\
& <\liminf _{j \rightarrow \infty}\left\|x_{n_{j}}-\bar{x}\right\|=\lim _{n \rightarrow \infty}\left\|x_{n}-\bar{x}\right\| .
\end{aligned}
$$

This derives a contradiction. Hence, we have $\bar{x}=x^{\prime}$. This implies that $x_{n} \rightarrow \bar{x} \in \mathcal{F}$. The proof is completed.

From Theorem 2.1, the following result is not hard to derive. 
Corollary 2.2 Let $C$ be a nonempty closed convex subset of a real Hilbert space $H$. Let $F$ be a bifunction from $C \times C$ to $\mathbb{R}$ which satisfies (A1)-(A4). Let $S: C \rightarrow C$ be a k-strict pseudocontraction. Assume that $\mathcal{F}:=\mathrm{EP}(F) \cap F(S)$ is not empty. Let $\left\{\alpha_{n}\right\},\left\{\beta_{n}\right\},\left\{\gamma_{n}\right\}$ and $\left\{\delta_{n}\right\}$ be sequences in $(0,1)$. Let $\left\{r_{n}\right\}$ be a positive number sequence, and let $\left\{e_{n}\right\}$ be a bounded sequence in C. Let $\left\{x_{n}\right\}$ be a sequence generated in the following manner:

$$
\left\{\begin{array}{l}
x_{1} \in C, \\
F\left(u_{n}, u\right)+\frac{1}{r_{n}}\left\langle u-u_{n}, u_{n}-x_{n}\right\rangle \geq 0 \quad \forall u \in C, \\
x_{n+1}=\alpha_{n} x_{n}+\beta_{n}\left(\delta_{n} u_{n}+\left(1-\delta_{n}\right) S u_{n}\right)+\gamma_{n} e_{n} \quad \forall n \geq 1 .
\end{array}\right.
$$

Assume that the sequences $\left\{\alpha_{n}\right\},\left\{\beta_{n}\right\},\left\{\gamma_{n}\right\},\left\{\delta_{n}\right\}$ and $\left\{r_{n}\right\}$ satisfy the following restrictions: $0<a \leq \alpha_{n} \leq a^{\prime}<1,0 \leq k \leq \delta_{n} \leq b<1,0<c \leq r_{n} \leq d<+\infty$ and $\sum_{n=1}^{\infty} \gamma_{n}<\infty$. Then the sequence $\left\{x_{n}\right\}$ converges weakly to some point $\bar{x} \in \mathcal{F}$, where $\bar{x}=\lim _{n \rightarrow \infty} P_{\mathcal{F}} x_{n}$.

Corollary 2.3 Let $C$ be a nonempty closed convex subset of a real Hilbert space H. Let $T: C \rightarrow H$ be a $\lambda$-inverse-strongly monotone mapping, and let $F$ be a bifunction from $C \times C$ to $\mathbb{R}$ which satisfies (A1)-(A4). Let $S: C \rightarrow C$ be a nonexpansive mapping. Assume that $\mathcal{F}:=\mathrm{EP}(F, T) \cap F(S)$ is not empty. Let $\left\{\alpha_{n}\right\},\left\{\beta_{n}\right\}$ and $\left\{\gamma_{n}\right\}$ be sequences in $(0,1)$. Let $\left\{r_{n}\right\}$ be a positive real number sequence, and let $\left\{e_{n}\right\}$ be a bounded sequence in C. Let $\left\{x_{n}\right\}$ be a sequence generated in the following manner:

$$
\left\{\begin{array}{l}
x_{1} \in C, \\
F\left(u_{n}, u\right)+\left\langle T x_{n}, u-u_{n}\right\rangle+\frac{1}{r_{n}}\left\langle u-u_{n}, u_{n}-x_{n}\right\rangle \geq 0 \quad \forall u \in C, \\
x_{n+1}=\alpha_{n} x_{n}+\beta_{n} S u_{n}+\gamma_{n} e_{n} \quad \forall n \geq 1 .
\end{array}\right.
$$

Assume that the sequences $\left\{\alpha_{n}\right\},\left\{\beta_{n}\right\},\left\{\gamma_{n}\right\}$ and $\left\{r_{n}\right\}$ satisfy the following restrictions: $0<$ $a \leq \alpha_{n} \leq a^{\prime}<1,0<c \leq r_{n} \leq d<2 \lambda$ and $\sum_{n=1}^{\infty} \gamma_{n}<\infty$. Then the sequence $\left\{x_{n}\right\}$ converges weakly to some point $\bar{x} \in \mathcal{F}$, where $\bar{x}=\lim _{n \rightarrow \infty} P_{\mathcal{F}} x_{n}$.

\section{Applications}

The computation of common fixed points is important in the study of many real world problems, including inverse problems; for instance, it is not hard to show that the split feasibility problem and the convex feasibility problem in signal processing and image reconstruction can both be formulated as a problem of finding fixed points of certain operators, respectively; for more details, see $[35,36]$ and the references therein.

First, we consider the following common fixed point problem.

Theorem 3.1 Let $C$ be a nonempty closed convex subset of a real Hilbert space H. Let $S_{m}: C \rightarrow C$ be a $k_{m}$-strict pseudocontraction for each $1 \leq m \leq N$, where $N$ is some positive integer. Assume that $\mathcal{F}:=\bigcap_{m=1}^{\infty} F(S)$ is not empty. Let $\left\{\alpha_{n}\right\},\left\{\beta_{n}\right\}$ and $\left\{\gamma_{n}\right\}$ be sequences in $(0,1)$. Let $\left\{e_{n}\right\}$ be a bounded sequence in C. Let $\left\{x_{n}\right\}$ be a sequence generated in the following manner:

$$
x_{1} \in C, \quad x_{n+1}=\alpha_{n} x_{n}+\beta_{n}\left(\delta_{n} x_{n}+\left(1-\delta_{n}\right) \sum_{i=1}^{N} \mu_{i} S_{i} x_{n}\right)+\gamma_{n} e_{n} \quad \forall n \geq 1 .
$$


Assume that the sequences $\left\{\alpha_{n}\right\},\left\{\beta_{n}\right\},\left\{\gamma_{n}\right\},\left\{\delta_{n}\right\}$ and $\left\{r_{n}\right\}$ satisfy the following restrictions: $0<a \leq \alpha_{n} \leq a^{\prime}<1,0 \leq k \leq \delta_{n} \leq b<1,0<c \leq r_{n} \leq d<2 \lambda$ and $\sum_{n=1}^{\infty} \gamma_{n}<\infty$. Then the sequence $\left\{x_{n}\right\}$ converges weakly to some point $\bar{x} \in \mathcal{F}$, where $\bar{x}=\lim _{n \rightarrow \infty} P_{\mathcal{F}} x_{n}$.

Proof Using the definition of strict pseudocontractions, we see that a mapping $T$ is said to be a $k$-strict pseudocontraction iff

$$
\langle x-y,(I-T) x-(I-T) y\rangle \geq \frac{1-k}{2}\|(I-T) x-(I-T) y\|^{2} .
$$

Define a mapping $S: C \rightarrow C$ by $S=\sum_{m=1}^{N} \mu_{m} S_{m}$. Next, we prove that $F(S)=\bigcap_{m=1}^{N} F\left(S_{m}\right)$ and $S$ is a $k$-strict pseudocontraction, where $k=\max \left\{k_{m}: 1 \leq m \leq N\right\}$. Note that

$$
\begin{aligned}
\langle x-y,(I-S) x-(I-S) y\rangle & =\sum_{m=1}^{N} \mu_{m}\left\langle x-y,\left(I-S_{m}\right) x-\left(I-S_{m}\right) y\right\rangle \\
& \geq \sum_{m=1}^{N} \mu_{m} \frac{1-k_{m}}{2}\left\|\left(I-S_{m}\right) x-\left(I-S_{m}\right) y\right\|^{2} \\
& \geq \sum_{m=1}^{N} \mu_{m} \frac{1-k}{2}\left\|\left(I-S_{m}\right) x-\left(I-S_{m}\right) y\right\|^{2} \\
& \geq \frac{1-k}{2}\|(I-S) x-(I-S) y\|^{2} .
\end{aligned}
$$

This proves that $S$ is a $k$-strict pseudocontraction, where $k=\max \left\{k_{m}: 1 \leq m \leq N\right\}$. Next, we show that $F(S)=\bigcap_{m=1}^{N} F\left(S_{m}\right)$. It is clear to see that $F(S) \supseteq \bigcap_{m=1}^{N} F\left(S_{m}\right)$. It suffices to prove that $\bigcap_{m=1}^{N} F\left(S_{m}\right) \supseteq F(S)$. Let $x \in F(S)$ and write $T_{m}=I-S_{m}$. Let $y \in \bigcap_{m=1}^{N} F\left(S_{m}\right)$. For any $i, j \in\{1,2, \ldots, N\}$ and $i \neq j$, we have

$$
\begin{aligned}
\|x-y\|^{2} & =\left\|\sum_{m=1}^{N} \mu_{m}\left(y-S_{m} x\right)\right\|^{2} \\
& \leq \sum_{m=1}^{N} \mu_{m}\left\|y-S_{m} x\right\|^{2}-\mu_{i} \mu_{j}\left\|S_{i} x-S_{j} x\right\|^{2} \\
& \leq \sum_{m=1}^{N} \mu_{m}\left(\|y-x\|^{2}+k_{m}\left\|T_{m} x\right\|^{2}\right)-\mu_{i} \mu_{j}\left\|S_{i} x-S_{j} x\right\|^{2} \\
& \leq\|y-x\|^{2}+k \sum_{i=1}^{N} \mu_{m}\left\|T_{m} x\right\|^{2}-\mu_{i} \mu_{j}\left\|S_{i} x-S_{j} x\right\|^{2} .
\end{aligned}
$$

This shows that

$$
\mu_{i} \mu_{j}\left\|S_{i} x-S_{j} x\right\|^{2} \leq k \sum_{m=1}^{N} \mu_{m}\left\|T_{m} x\right\|^{2} .
$$

Since $\sum_{i=1}^{N} \mu_{m} T_{m} x=0$, we find that $\left\|S_{i} x-S_{j} x\right\|=0$. This proves that $S_{i} x=S_{j} x$. Since $x$ is a fixed point of $S$, we obtain $\bigcap_{m=1}^{N} F\left(S_{m}\right) \supseteq F(S)$. This proves that $F(S)=\bigcap_{m=1}^{N} F\left(S_{m}\right)$. Putting $T=0, F=0$ and $r_{n}=1$, we find from Theorem 2.1 the desired conclusion immediately. 
Next, we study an optimization problem: Find a minimizer of a convex and lower semicontinuous functional $h(x)$ defined on a closed convex subset $C$ of a Hilbert space $H$.

We denote by $\Delta$ the set of solutions of the optimization problem. Let $R$ be a bifunction from $C \times C$ to $R$ defined by $R(x, y)=h(y)-h(x)$. We consider the following equilibrium problem:

$$
\text { Find } x \in C \text { such that } R(x, y) \geq 0 \quad \forall y \in C \text {. }
$$

It is obvious that $\operatorname{EP}(R)=\Delta$. In addition, we also find that $R(x, y)$ satisfies the conditions (A1)-(A4).

Theorem 3.2 Let C be a nonempty closed convex subset of a real Hilbert space H. Let $h(x)$ be a convex and lower semicontinuous functional defined on $C$ with a nonempty minimizer set. Let $\left\{\alpha_{n}\right\},\left\{\beta_{n}\right\}$ and $\left\{\gamma_{n}\right\}$ be sequences in $(0,1)$. Let $\left\{r_{n}\right\}$ be a positive real number sequence, and let $\left\{e_{n}\right\}$ be a bounded sequence in $C$. Let $\left\{x_{n}\right\}$ be a sequence generated in the following manner:

$$
\left\{\begin{array}{l}
x_{1} \in C, \\
h(u)-h\left(u_{n}\right)+\frac{1}{r_{n}}\left\langle u-u_{n}, u_{n}-x_{n}\right\rangle \geq 0 \quad \forall u \in C, \\
x_{n+1}=\alpha_{n} x_{n}+\beta_{n} u_{n}+\gamma_{n} e_{n} \quad \forall n \geq 1 .
\end{array}\right.
$$

Assume that the sequences $\left\{\alpha_{n}\right\},\left\{\beta_{n}\right\},\left\{\gamma_{n}\right\}$ and $\left\{r_{n}\right\}$ satisfy the following restrictions: $0<a \leq$ $\alpha_{n} \leq a^{\prime}<1,0 \leq k \leq \delta_{n} \leq b<1,0<c \leq r_{n} \leq d<+\infty$ and $\sum_{n=1}^{\infty} \gamma_{n}<\infty$. Then the sequence $\left\{x_{n}\right\}$ converges weakly to some point $\bar{x} \in \Delta$, where $\bar{x}=\lim _{n \rightarrow \infty} P_{\Delta} x_{n}$.

Remark 3.3 A special form of the optimization problem is to take $h(x)=\|x\|$, which is known as the minimum norm point problem. We also remark here that if we take $F=0$ and $S=I$, then we easily obtain convergence theorems of solutions of variational inequality (1.3).

\section{Competing interests}

The authors declare that they have no competing interests.

\section{Authors' contributions}

The main idea of this paper was proposed by $\mathrm{CH}$. All authors participated in the research and performed steps of the proof in this research. All authors read and approved the final manuscript.

\section{Author details}

${ }^{1}$ School of Mathematics and Information Science, North China University of Water Resources and Electric Power,

Zhengzhou, 450011, China. ${ }^{2}$ Basic Experimental \& Teaching Center, Henan University, Kaifeng, 475000, China.

Received: 29 March 2014 Accepted: 14 June 2014 Published: 22 July 2014

\section{References}

1. Blum, E, Oettli, W: From optimization and variational inequalities to equilibrium problems. Math. Stud. 63, 123-145 (1994)

2. Barbagallo, $\mathrm{A}$ : On the regularity of retarded equilibria in time-dependent traffic equilibrium problems. Nonlinear Anal. 71, e2406-e2417 (2009)

3. Qin, X, Agarwal, RP: Shrinking projection methods for a pair of asymptotically quasi- $\boldsymbol{\phi}$-nonexpansive mappings. Numer. Funct. Anal. Optim. 31, 1072-1089 (2001)

4. Park, S: A review of the KKM theory on $\phi_{A}$-space or GFC-spaces. Adv. Fixed Point Theory 3, 355-382 (2013)

5. Noor, MA, Noor, KI, Waseem, M: Decomposition method for solving system of linear equations. Eng. Math. Lett. 2 , 34-41 (2012) 
6. Cho, SY, Qin, X, Kang, SM: Iterative processes for common fixed points of two different families of mappings with applications. J. Glob. Optim. 57, 1429-1446 (2013)

7. Barbagallo, $A$, Daniele, $P$, Maugeri, A: Variational formulation for a general dynamic financial equilibrium problem: balance law and liability formula. Nonlinear Anal. 75, 1104-1123 (2012)

8. Nilsrakoo, W, Saejung, S: Weak and strong convergence theorems for countable Lipschitzian mappings and its applications. Nonlinear Anal. 69, 2695-2708 (2008)

9. Cho, SY, Qin, X, Wang, L: Strong convergence of a splitting algorithm for treating monotone operators. Fixed Point Theory Appl. 2014, Article ID 94 (2014)

10. He, RH: Coincidence theorem and existence theorems of solutions for a system of Ky Fan type minimax inequalities in FC-spaces. Adv. Fixed Point Theory 2, 47-57 (2012)

11. Agarwal, RP, O'Regan, D: Fixed point theory for maps with lower semicontinuous selections and equilibrium theory for abstract economies. J. Nonlinear Convex Anal. 2, 31-46 (2001)

12. Cho, SY, Qin, X: On the strong convergence of an iterative process for asymptotically strict pseudocontractions and equilibrium problems. Appl. Math. Comput. 235, 430-438 (2014)

13. Kim, JK, Anh, PN, Nam, YM: Strong convergence of an extended extragradient method for equilibrium problems and fixed point problems. J. Korean Math. Soc. 49, 187-200 (2012)

14. Tada, A, Takahashi, W: Weak and strong convergence theorems for a nonexpansive mapping and an equilibrium problem. J. Optim. Theory Appl. 133, 359-370 (2007)

15. Qin, X, Cho, SY, Kang, SM: Strong convergence of shrinking projection methods for quasi- $\phi$-nonexpansive mappings and equilibrium problems. J. Comput. Appl. Math. 234, 750-760 (2010)

16. Chen, JH: Iterations for equilibrium and fixed point problems. J. Nonlinear Funct. Anal. 2013, Article ID 4 (2013)

17. Kim, JK: Strong convergence theorems by hybrid projection methods for equilibrium problems and fixed point problems of the asymptotically quasi- $\phi$-nonexpansive mappings. Fixed Point Theory Appl. 2011, Article ID 10 (2011)

18. Qin, X, Cho, SY, Kang, SM: An extragradient-type method for generalized equilibrium problems involving strictly pseudocontractive mappings. J. Glob. Optim. 49, 679-693 (2011)

19. Wu, C, Liu, A: Strong convergence of a hybrid projection iterative algorithm for common solutions of operator equations and of inclusion problems. Fixed Point Theory Appl. 2012, Article ID 90 (2012)

20. Cho, SY, Kang, SM: Approximation of common solutions of variational inequalities via strict pseudocontractions. Acta Math. Sci. 32, 1607-1618 (2012)

21. Rodjanadid, B, Sompong, S: A new iterative method for solving a system of generalized equilibrium problems, generalized mixed equilibrium problems and common fixed point problems in Hilbert spaces. Adv. Fixed Point Theory 3, 675-705 (2013)

22. Ye, J, Huang, J: Strong convergence theorems for fixed point problems and generalized equilibrium problems of three relatively quasi-nonexpansive mappings in Banach spaces. J. Math. Comput. Sci. 1, 1-18 (2011)

23. Cho, SY, Li, W, Kang, SM: Convergence analysis of an iterative algorithm for monotone operators. J. Inequal. Appl. 2013, Article ID 199 (2013)

24. Zhang, M: Iterative algorithms for common elements in fixed point sets and zero point sets with applications. Fixed Point Theory Appl. 2012, Article ID 21 (2012)

25. Zhang, M: Strong convergence of a viscosity iterative algorithm in Hilbert spaces. J. Nonlinear Funct. Anal. 2014, Article ID 1 (2014)

26. Qin, $X$, Cho, SY, Kang, SM: Iterative algorithms for variational inequality and equilibrium problems with applications J. Glob. Optim. 48, 423-445 (2010)

27. Browder, FE, Petryshyn, WV: Construction of fixed points of nonlinear mappings in Hilbert space. J. Math. Anal. Appl. 20, 197-228 (1967)

28. Rockafellar, RT: On the maximality of sums of nonlinear monotone operators. Trans. Am. Math. Soc. 149, 75-88 (1970)

29. Fan, K: A minimax inequality and applications. In: Shisha, O (ed.) Inequalities III, pp. 103-113. Academic Press, New York (1972)

30. Takahashi, W, Toyoda, M: Weak convergence theorems for nonexpansive mappings and monotone mappings. J. Optim. Theory Appl. 118, 417-428 (2003)

31. Zhou, $\mathrm{H}$ : Convergence theorems of fixed points for $k$-strict pseudo-contractions in Hilbert spaces. Nonlinear Anal. 69 456-462 (2008)

32. Schu, J: Weak and strong convergence of fixed points of asymptotically nonexpansive mappings. Bull. Aust. Math. Soc. 43, 153-159 (1991)

33. Acedo, GL, Xu, HK: Iterative methods for strict pseudo-contractions in Hilbert spaces. Nonlinear Anal. 67, 2258-2271 (2007)

34. Opial, Z: Weak convergence of the sequence of successive approximation for nonexpansive mappings. Bull. Am. Math. Soc. 73, 591-597 (1967)

35. VanderLugt, A: Optical Signal Processing. Wiley, New York (2005)

36. Byrne, C: A unified treatment of some iterative algorithms in signal processing and image reconstruction. Inverse Probl. 20, 103-120 (2008)

doi:10.1186/1687-1812-2014-145

Cite this article as: Huang and Ma: On generalized equilibrium problems and strictly pseudocontractive mapping

in Hilbert spaces. Fixed Point Theory and Applications 2014 2014:145. 